\title{
Functional recovery in patients with schizophrenia: recommendations from a panel of experts
}

\author{
Guillermo Lahera ${ }^{1,2}$, José L. Gálvez ${ }^{3}$, Pedro Sánchez ${ }^{4,5}$, Miguel Martínez-Roig ${ }^{6}$, J. V. Pérez-Fuster ${ }^{7}$,
} Paz García-Portilla ${ }^{2,8}$, Berta Herrera ${ }^{9}$ and Miquel Roca ${ }^{10^{*}}$

\begin{abstract}
Background: The management of schizophrenia is evolving towards a more comprehensive model based on functional recovery. The concept of functional recovery goes beyond clinical remission and encompasses multiple aspects of the patient's life, making it difficult to settle on a definition and to develop reliable assessment criteria. In this consensus process based on a panel of experts in schizophrenia, we aimed to provide useful insights on functional recovery and its involvement in clinical practice and clinical research.

Methods: After a literature review of functional recovery in schizophrenia, a scientific committee of 8 members prepared a 75-item questionnaire, including 6 sections: (I) the concept of functional recovery (9 items), (II) assessment of functional recovery (23 items), (III) factors influencing functional recovery (16 items), (IV) psychosocial interventions and functional recovery (8 items), ( $V$ pharmacological treatment and functional recovery (14 items), and (VI) the perspective of patients and their relatives on functional recovery ( 5 items). The questionnaire was sent to a panel of 53 experts, who rated each item on a 9-point Likert scale. Consensus was achieved in a 2-round Delphi dynamics, using the median (interquartile range) scores to consider consensus in either agreement (scores 7-9) or disagreement (scores 1-3). Items not achieving consensus in the first round were sent back to the experts for a second consideration.

Results: After the two recursive rounds, consensus was achieved in 64 items (85.3\%): 61 items (81.3\%) in agreement and 3 (4.0\%) in disagreement, all of them from section II (assessment of functional recovery). Items not reaching consensus were related to the concepts of functional recovery (1 item, 1.3\%), functional assessment (5 items, 6.7\%), factors influencing functional recovery (3 items, 4.0\%), and psychosocial interventions (2 items, 5.6\%).

Conclusions: Despite the lack of a well-defined concept of functional recovery, we identified a trend towards a common archetype of the definition and factors associated with functional recovery, as well as its applicability in clinical practice and clinical research.
\end{abstract}

Keywords: Schizophrenia, Functional recovery, Psychosocial therapy, Antipsychotic agents

\footnotetext{
* Correspondence: mroca@uib.es

${ }^{10}$ Institut Universitari d'Investigació en Ciencies de la Salut (IUNIS), RedIAPP, Hospital Juan March, Universidad de las Islas Baleares, Cra. de Valldemossa, km 7.5., Palma de Mallorca, (Illes Balears), Spain

Full list of author information is available at the end of the article
}

(c) The Author(s). 2018 Open Access This article is distributed under the terms of the Creative Commons Attribution 4.0 International License (http://creativecommons.org/licenses/by/4.0/), which permits unrestricted use, distribution, and reproduction in any medium, provided you give appropriate credit to the original author(s) and the source, provide a link to the Creative Commons license, and indicate if changes were made. The Creative Commons Public Domain Dedication waiver (http://creativecommons.org/publicdomain/zero/1.0/) applies to the data made available in this article, unless otherwise stated. 


\section{Background}

The management of schizophrenia has traditionally focused on the assessment of symptomatology and neurocognitive functioning [1]. However, there is increasing interest in developing more comprehensive models focusing on functional recovery [2-9]. Unlike clinical remission, which is well defined and can be measured, the concept of recovery encompasses multiple aspects of the patient's life, making it difficult to settle on a definition and to develop reliable assessment criteria. Liberman and colleagues [10] proposed operational criteria for recovery from schizophrenia that included symptom remission, improved vocational functioning, independent living, and improved peer relationships. In contrast, Anthony [11] described functional recovery as a deeply personal, unique process of changing one's attitudes, values, feelings, goals, skills, and/or roles, even with limitations caused by illness. On the other hand, some clinicians have warned that functional recovery can only be accepted when symptoms are mild and stable enough to not interfere with normal functioning in social activities and relationships [6, 12]. Regardless of the perspective of the various stakeholders, it is widely accepted that functional recovery is influenced by the severity of symptoms as well as by disease-related aspects such as neurocognitive performance [7, 13-15]. Additionally, social and family circumstances, opportunities, and lifetime events contribute to extending the list of environmental factors that may influence functional recovery beyond clinical manifestations of schizophrenia [7, 15, 16].

Patients with schizophrenia now have access to a wide variety of pharmacological agents and psychosocial therapies which may eventually meet the particular needs of each patient profile and, therefore, increase the chances of positive therapeutic outcomes [17]. The lack of standardized tools for the assessment of functional recovery prevents from drawing strong conclusions regarding the contribution of these interventions to functional recovery in patients with schizophrenia. Nevertheless, results of clinical studies - including randomized controlled trials - on various interventions for schizophrenia suggest that the achievement of functional recovery is possible in many cases [18-21].

Due to the heterogeneity of published information and the limited empirical evidence on functional recovery, this concept is not commonly considered an assessment criterion and/or a therapeutic goal in most clinical practice guidelines [1]. In a non-standardized way, most clinicians are familiar with the concept of functional recovery and consider it useful in their day-to-day practice [22]. Nevertheless, it is not clear whether clinicians have a common construct of functional recovery and to what extent these ideas meet the empirical evidence published in the literature. We present herein the results of a Delphi consensus process aimed to identify commonly accepted concepts regarding the definition and assessment of functional recovery, as well as the perceived impact of psychosocial and pharmacological interventions on its attainment.

\section{Methods \\ Design of the consensus dynamics}

The aim of this consensus was to apprise various aspects related to the assessment and functional intervention of patients with schizophrenia and provide clinicians and investigators with insights into functional recovery in patients with schizophrenia. The consensus process was approached through two recursive rounds of Delphi dynamics. The Delphi methodology is a structured, systematic, and interactive forecasting method based on the individual judgments of a panel of experts [23, 24]. The two Delphi rounds were held between May 5th 2016 and July 1st 2016. In each round, experts anonymously acceded to an online questionnaire and rated each item in the questionnaire on a 9-point Likert scale, where lower scores meant disagreement and higher scores meant agreement. For each item, consensus was considered when at least two-thirds of the experts scored either 1-to-3 (disagree) or 7-to-9 (agree) (Additional file 1: Table S1). Conversely, non-consensus was considered when the interquartile range (i.e. percentiles 25-75) was greater than 4 or when one-third of the experts or more scored either 1-to-3 or 7-to-9. In that case an indeterminate level was assigned to items not meeting the criteria for either consensus or non-consensus. Items not achieving consensus in the first round were sent back to the experts for a second assessment round.

Using bar graphs, a research assistance team, which did not interfere in the responses, assessed and presented the results from the first round to facilitate comments and clarifications from each participant. In the second round, the expert panelists contrasted their personal opinion with the result of the first round and, if necessary, reconsidered their initial opinion on those items in which consensus was not reached. The results of this second round were tabulated and presented descriptively using the median and interquartile range and the percentage of experts agreeing/disagreeing a particular statement.

At the end of the Delphi process, the scientific committee discussed the final results during a group session, held on October 15th, 2016. A manuscript was drafted with the conclusions drawn from the responses of the panel of experts and the literature review, which was revised and approved by all members of the scientific committee. 


\section{Participants}

The scientific committee consisted of eight psychiatrists from Spanish hospitals. Each member of the scientific committee proposed and recruited psychiatrists from Spanish hospitals, outpatient units, and academic settings to participate in the panel of experts. To be included in the panel, the expert must have at least 10 years of experience in a hospital setting. To prevent attrition bias between the two rounds, only experts who completed the entire Delphi process were to be listed in the acknowledgement section of the publication [25]. The research assistance team, led by $\mathrm{BH}$, directed and oversaw the entire process and was responsible for the distribution and analysis of the questionnaires.

\section{The questionnaire}

After a literature review of the empirical evidence and expert opinions on functional recovery in patients with schizophrenia, the members of the scientific committee discussed the unmet needs regarding the definition of functional recovery and its assessment, as well as the possible interventions to accomplish it. The items of interest were summarized in a questionnaire of 75 items, which were grouped into six sections: (I) the concept of functional recovery (9 items), (II) assessment of functional recovery (23 items), (III) factors influencing functional recovery (16 items), (IV) psychosocial interventions and functional recovery (8 items), (V) pharmacological treatment and functional recovery (14 items), and (VI) the perspective of patients and their relatives on functional recovery (5 items). The questionnaire was sent to the experts in the panel for their consideration.

\section{Results}

\section{Consensus overview}

Based on the criteria of the members of the scientific committee, 80 experts were invited to participate in the Delphi process. Of them, 53 responded the first round and 53 in the second one, indicating no drop out between the two recursive rounds of the Delphi process. In the first round, consensus was achieved in 41 items (54.7\%), all of them in agreement. Of the 34 items addressed in the second round, 23 met the consensus criteria (20 items in agreement and 3 in disagreement), yielding a final consensus list of64 items (85.3\%): 61 $(81.3 \%)$ in agreement and $3(4.0 \%)$ in disagreement. Table 1 shows the number and percentages of items in each section on which the experts reached agreement (i.e. consensus on the score range 7-to-9), disagreement (i.e. consensus on the score range 1-to-3), and lack of consensus. Of eleven items not meeting the consensus criteria, one resulted in non-consensus (i.e. more than one-third of experts scoring 1-to-3 and more than one-third scoring 7-to-9) and ten were indeterminate
Table 1 Consensus rate in each section of the questionnaire

\begin{tabular}{lcc}
\hline & No. & $\%$ \\
\hline I. The concept of functional recovery $(n=9)$ & \\
Agreement & 8 & $88.9 \%$ \\
Disagreement & 0 & - \\
No consensus & 1 & $11.1 \%$ \\
II. Functional assessment $(n=22)$ & \\
Agreement & 15 & $68.2 \%$ \\
Disagreement & 3 & $13.6 \%$ \\
No consensus & 5 & $22.7 \%$ \\
III. Factors influencing functional recovery $(n=16)$ & \\
Agreement & 13 & $81.3 \%$ \\
Disagreement & 0 & - \\
No consensus & 3 & $18.8 \%$ \\
IV. Psychosocial interventions and functional recovery $(n=8)$ \\
Agreement & 6 & $75.0 \%$ \\
Disagreement & 0 & - \\
No consensus & 2 & - \\
V. Functioning and pharmacological treatment $(n=14)$ \\
Agreement & 14 & $100 \%$ \\
Disagreement & 0 & - \\
No consensus & 0 & - \\
VI. the perspective of patients and their relatives on functional recovery \\
$(n=5)$ \\
Agreement & 5 & \\
Disagreement & 0 & - \\
No consensus & & \\
\hline
\end{tabular}

(i.e. not meeting criteria for either consensus or non-consensus) (Fig. 1). Most items not reaching consensus belonged to the functional assessment section (5 items, 6.7\%), followed by factors influencing functional recovery (3 items, $4.0 \%$ ), psychosocial interventions and functional recovery ( 2 items, 5.6\%), and the concept of functional recovery (1 item, 1.3\%). Additional file 1: Tables S2-S7 provide details on the median and interquartile range obtained on each item. The median score in items meeting the consensus criteria ranged from 6.06 to 8.31 .

\section{The concept of functional recovery}

Additional file 1: Table S2 summarizes the median scores of the 9 items regarding the concept of functional recovery. The experts did not reach a consensus regarding the existence of a standardized concept of functional recovery in patients with schizophrenia $57.7 \%$ of agreement; median score 7.06; 95\%CI 6.50-7.50). Nevertheless, the experts in the panel overall agreed on each one of the multiple characteristics frequently included in the definition of functional recovery. For instance, most 
a

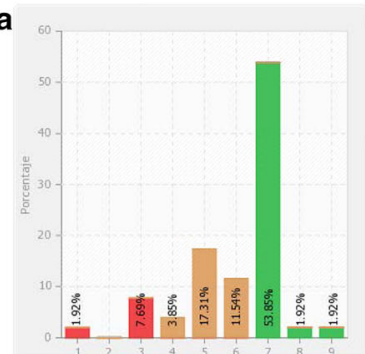

d

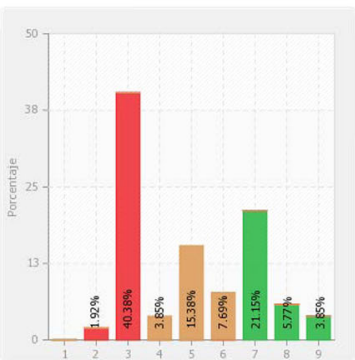

g

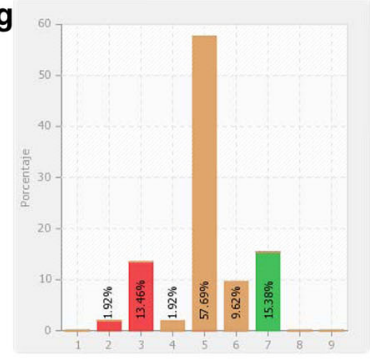

j

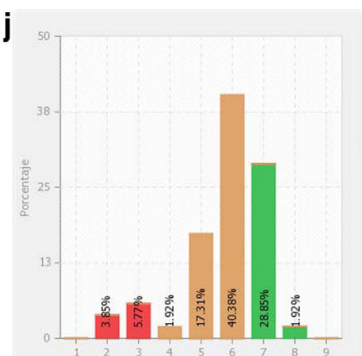

b

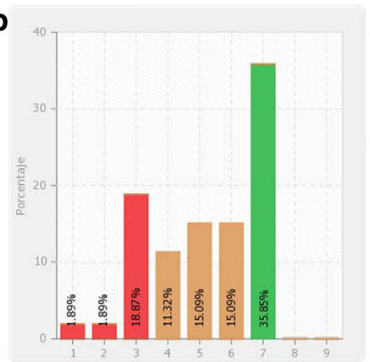

e

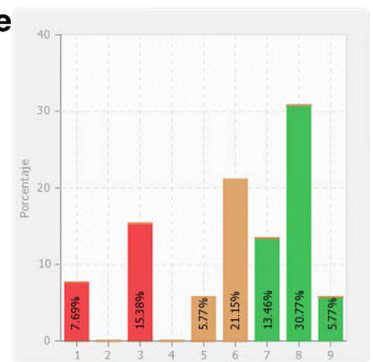

h

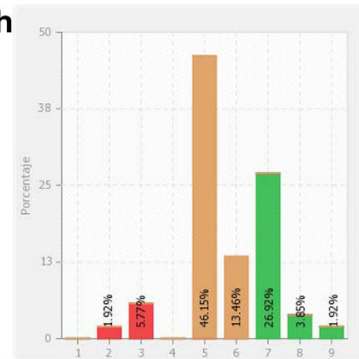

k

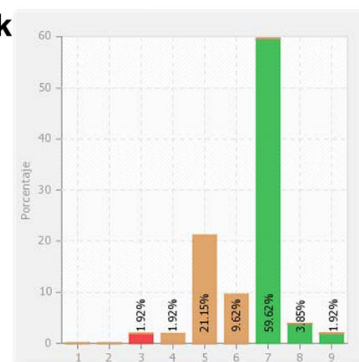

c

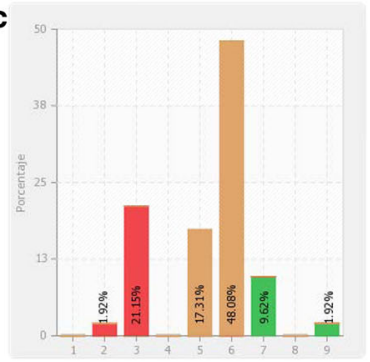

$\mathbf{f}$

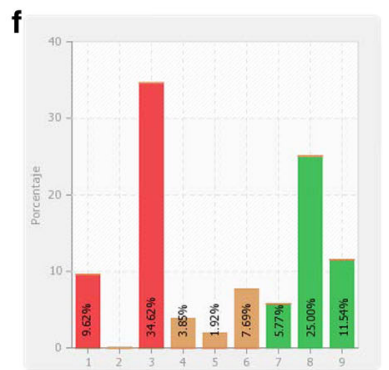

i

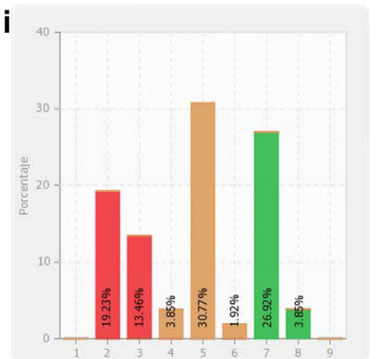

Fig. 1 Results of the items not meeting the consensus criteria. a functional recovery is a well-established concept. $\mathbf{b}$ The functional assessment is commonly included among the objectives of clinical trials on schizophrenia. $\mathbf{c}$ the patient is the most reliable source of information for functional assessment. $\mathbf{d}$ : a proper functional assessment is not affordable in institutionalized patients. e I am familiar with the use of the Social and Occupational Functioning Assessment Scale (SOFAS) regarding the functional assessment of schizophrenic patients. $\mathbf{f} I$ am familiar with the use of the Health of the Nation Outcome Scales (HoNOS) regarding the functional assessment of schizophrenic patients. $\mathbf{g}$ living in an urban area is the environmental factor that has the greatest impact on functioning in patients with schizophrenia. $\mathbf{h}$ being an immigrant is the environmental factor that has the greatest impact on functioning in patients with schizophrenia. i: Public campaigns aimed at reducing stigma in patients with schizophrenia are effective. $\mathbf{j}$ cognitive-behavioral therapy is the most effective psychosocial intervention for functional recovery. $\mathbf{k}$ cognitive disorders should be the primary target of psychosocial interventions

experts agreed that functional recovery overlaps with other concepts such as quality of life, cognition, and clinical remission. Furthermore, experts identified the influence of symptomatic remission, personal autonomy, professional activity, social relationships, and environmental factors on functional recovery. According to $86.5 \%$ of the experts, functional recovery is an achievable goal in patients with schizophrenia.

\section{Assessment of functional recovery}

According to the experts, the assessment of functional recovery is essential in both the clinical research and clinical practice settings (96.2\% of consensus). However, there was no consensus on whether the assessment of functional recovery is commonly included among study objectives of clinical trials in schizophrenia (Additional file 1: Table S3). 
Regarding the source of information for the assessment of functional recovery, there was strong agreement (98.1\%) on the suitability of gathering information from three primary sources: patients, their relatives (and/or caregivers), and clinicians. The experts exhibited heterogeneous knowledge of the functional assessment tools currently available for identifying areas subject to improvement, and planning the management of patients with schizophrenia. Most of them stated that they were familiar with the GAF scale, the Personal and Social Performance scale (PSP), and the second version of the World Health Organization Disability Assessment Schedule (WHODAS 2.0). Conversely, the majority of experts were not familiar with the Social and Occupational Functioning Assessment Scale (SOFAS) or the Health of the Nation Outcome Scale (HoNOS). Beyond the scales used, it was suggested that functional recovery is somehow assessed in routine practice, albeit without any standardized procedure.

\section{Factors influencing functional recovery}

The experts overall agreed that functional recovery is influenced by various environmental factors, including stressful life events, substance abuse, socioeconomic conditions, and family dynamics (Additional file 1: Table S4). However, most of them (90\%) acknowledged that none of these factors predicts independently the non-achievement of functional recovery. Other environmental factors such as the type of origin (i.e. migrant/ local) and residence (i.e. urban/rural) were not considered to influence functional recovery significantly. Both negative and cognitive symptoms were considered to cause significant impact on functional recovery, with no superiority of either of the two symptom groups. Finally, the experts agreed that self-stigma (or internalized stigma) has a greater impact on functional recovery than social stigma. The idea that the negative image associated with psychiatry compared to other medical specialties increases stigma in patients with schizophrenia also reached a consensus in agreement.

\section{Psychosocial interventions and functional recovery}

There was overall agreement that psychosocial interventions are necessary to achieve functional recovery $(92.3 \%$ of agreement). Among all interventions proposed, family interventions and those aimed at developing social skills and improving employability were considered the most useful for functional recovery (Additional file 1: Table S5). Although the inclusion of cognitive rehabilitation in psychosocial interventions was considered useful, cognitive disorders were not agreed to be the primary target of these interventions.

\section{Pharmacological treatment and functional recovery}

The majority of experts in the panel (79.0\%) considered that functional recovery is one of the most important criteria determining the choice of pharmacological treatment (Additional file 1: Table S6). It was also agreed that the various antipsychotic agents have different impacts on functional recovery. Among the potential drawbacks of pharmacological treatment for achieving functional recovery, cognitive impairment reached the highest agreement (100\%); $94.3 \%$ of the experts agreed that second-generation are more useful than first-generation (or atypical) antipsychotics for achieving functional recovery.

\section{The perspective of patients and their relatives on functional recovery}

The experts agreed that the perspective of clinicians on functional recovery differed significantly from that of patients and their relatives (Additional file 1: Table S7). According to this observation, psychiatrists are more concerned with the clinical aspects of the disease, whereas patients and their relatives are more concerned with subjective aspects of the lifetime project and factors influencing activities of daily living.

\section{Discussion}

Following a two-round Delphi dynamics approach, we found high homogeneity in the opinion of clinicians regarding functional recovery in patients with schizophrenia. Psychiatrists from different areas in Spain achieved consensus in $85 \%$ of the concepts addressed regarding various aspects of functional recovery.

Functional recovery is a complex, multidimensional concept to be considered not only by clinicians but also researchers, patients and caregivers, as well mental health policy makers. Although the perspective of the various stakeholders involved in the definition of functional recovery may converge on many aspects, the lack of a common terminology and the pursuit of different goals has led to a wide repertoire of definitions, none of which stands out clearly over the rest $[2,6,7,16,26]$. The result of our consensus regarding the concept of functional recovery mirrored this scenario, resulting in a lack of consensus regarding a well-established concept of functional recovery. Nevertheless, the general agreement on specific factors influencing the concept of functional recovery suggests that despite the lack of a standardized definition of recovery, most clinicians share a common archetype of what functional recovery actually is.

The feasibility of achieving functional recovery in patients with schizophrenia has been under discussion since the emergence of interest in this concept $[2,6$, $22,27]$. Most experts in our panel $(87 \%)$ agreed that functional recovery is a realistic goal in the management of patients with schizophrenia. This is in line with the results of recent research on schizophrenia, 
which showed that psychological well-being and mental health recovery can improve in individuals with first-episode psychosis [28]. The lack of a clear definition and assessment tools prevents from drawing strong conclusions regarding the feasibility of a therapeutic model based on the concept of recovery. However, empirical evidence on various therapeutic interventions suggests that many patients with schizophrenia can achieve goals related to functional recovery such as independent living and competitive employment and education in routine community settings [18-21, 29]. In line with the common perception regarding the definition of functional recovery, M. Farkas proposed four key values commonly reflected in the recovery literature which should be considered in all recovery-oriented services: person orientation, person involvement, self-determination/choice, and growth potential [30].

The lack of a standardized definition is probably a bottleneck for the development of validated tools for the assessment of functional recovery. Other difficulties that may compromise an appropriate assessment of functional recovery include the limitations of some informants to make accurate judgments [31], the limited capacity of some patients for self-assessment [32], and the heterogeneity in their clinical course, which may lead to inconsistencies between the outcome of functioning scales and milestone achievement in some patients (e.g., in some patients, functioning scales may not capture milestone achievements in social, vocational, and residential domains of patients with schizophrenia) [33]. Regarding the source of information for the assessment of functional recovery, there was strong agreement on the suitability of gathering information from three primary sources: patients, their relatives (and/or caregivers), and clinicians. Indeed, some authors have warned of the risk of bias associated with motivation-related negative symptoms (e.g. emotional withdrawal, passive-apathetic social withdrawal) [34]. Furthermore, patient-reported assessments of quality of life and everyday abilities have shown poor correlation with information about lifetime achievements in many patients with schizophrenia [35]. All these limitations are consistent with the lack of consensus on the concept that the patient is the most reliable source of information for functional assessment.

Due to the absence of a single tool for the assessment of functional recovery, clinicians and researchers use different strategies to evaluate it. In an attempt to broaden functional assessment towards a comprehensive model of functional recovery, researchers have combined commonly used scales such as the Global Assessment Functioning (GAF) scale and Global Assessment Scale (GAS) with the Social Functioning Rating Score - which includes both social skills and social roles - and other objective indicators of lifetime achievements [36-38].
The experts exhibited heterogeneous knowledge of the functional assessment tools currently available for identifying areas subject to improvement, and planning the management of patients with schizophrenia. Beyond the scales used, it was suggested that functional recovery is somehow assessed in routine practice, albeit without any standardized procedure. In this regard, treatments based on a recovery model should be consistent with evidence-based treatments [2].

Functional recovery, may be influenced by multiple factors. According to the experts, these factors are a combination of environmental factors, stressful life events, substance abuse, socioeconomic conditions, and family dynamics. Other environmental factors such as the type of origin (i.e. migrant/local) and residence (i.e. urban/rural) were not considered to influence functional recovery significantly. Some authors have observed that patients living in rural areas tend to show better functional outcomes, probably due to greater family and social support as well as simpler vocational roles [39]. However, in our consensus, the experts' opinion might be strongly influenced by the area where they work. Thus, while some centers provide mental health care to patients from both rural and urban areas, most of them serve one or the other type, whereby the influence of this factor may be unnoticed. Finally, there was $96 \%$ agreement that, despite the different perspectives of clinicians and patients (i.e. clinicians tend to focus on the clinical aspects of recovery, whereas patients and their relatives attach importance to the activities of daily living and life project), the attitude of the various stakeholders has an influence on functional recovery.

In line with the results of clinical studies, which suggest that both negative symptoms and cognitive deficits may be primary predictors of impaired social and vocational performance $[34,40,41]$, the experts in the panel agreed that both negative and cognitive symptoms cause a significant impact on functional recovery. Also, in agreement with recent recommendations to treat negative symptoms [42], the experts agreed that functional recovery should not be addressed only through symptoms but also considering the cognitive, emotional, and relationship difficulties.

Stigma is another factor with potential influence on functional recovery, and it is generally accepted that it has a major impact on self-esteem and hampers recovery in people with mental illnesses $[7,43]$. The experts agreed that the negative image associated with psychiatry compared to other medical specialties increases stigma in patients with schizophrenia and that self-stigma (or internalized stigma) has a greater impact on functional recovery than social stigma. Although the mechanisms of stigma are not clear, social (or public) 
stigma and self-stigma might work in different ways. In an interview-based study conducted on patients with major depression or schizophrenia, social stigma showed a trend towards underestimating the importance of informal caregivers (e.g. family and friends). Conversely, self-stigma had a negative impact on the perceived importance of seeking help provided by a general practitioner or a psychiatrist [44].

The relevance of psychosocial interventions agreed in this consensus are consistent with the positive results of these interventions reported in randomized clinical trials conducted according to the gold standards of clinical design [45-47]. Although the items regarding the type of therapy with highest effectivity were written in an exclusive way, the experts achieved consensus in the highest effectivity of social skills training, family therapy, cognitive rehabilitation, social cognitive training, and occupational programs. This result indicates that, irrespective of the median score achieved in each therapy, none of them stood out from the rest. Of note, recovery-based interventions are not widespread in clinical practice and some authors have stressed the need to develop more interventions going beyond symptom reduction [48]. Although the inclusion of cognitive rehabilitation in psychosocial interventions was considered useful, cognitive disorders were not agreed to be the primary target of these interventions. The apparent inconsistency regarding the role of cognitive functioning in psychosocial interventions can be explained by the recent evolution of the concept of cognition. Thus, while the construct of cognitive impairment has been traditionally built solely on basic neurocognition, it is now accepted that social cognition differs from basic neurocognition and that it could be the link between neurocognition and functional recovery in psychosocial programming $[5,49]$.

The positive impact of long-acting antipsychotics on adherence and the closer relationship between patients and the healthcare team associated with the dosing of these agents have been considered helpful for achieving functional recovery [38]. Some authors have questioned the suitability of maintaining long-lasting treatment with antipsychotics [50]. However, the impact of long-lasting antipsychotic treatments on functional recovery is unclear, and other authors have highlighted important limitations of studies investigating early discontinuation of antipsychotic therapy [51].

Although it is not clear whether medication alone can impact directly on functional performance, there is long-time evidence on the synergistic effect of pharmacological and psychosocial treatments, particularly pharmacological treatments with a significant impact on positive symptoms [7, 52-54]. Besides attenuating the symptomatology associated with schizophrenia, pharmacological treatments - particularly atypical antipsychotic agents - cause morphological changes in patients' brains which could be associated with an improvement in neurochemical functioning $[55,56]$. Despite the proven usefulness of some antipsychotic agents in achieving functional recovery [57, 58], the experts identified potential drawbacks of pharmacological treatment for achieving functional recovery: extrapyramidal symptoms, sedation, the worsening of negative symptoms, and cognitive impairment. Of note, most of the adverse events limiting functional recovery are more frequently associated with first-generation than second-generation antipsychotics [59-61]. Combination antipsychotic therapy was also considered to result in poorer functional recovery than monotherapy.

Table 2 List of recommendations when addressing functional recovery of patients with schizophrenia

The concept of functional recovery

Despite the lack of a unified definition of functional recovery, it is recommended to ponder quality of life, cognition and clinical remission when considering functional recovery in research and routine practice.

Functional recovery should be considered a goal in the management of patients with schizophrenia.

Functional recovery should be always included among endpoints of clinical trials assessing patients with schizophrenia.

Assessment of functional recovery

Irrespective of the tools used for assessing functional recovery, information for appraising it should be gathered from patients, their relatives (and/or caregivers), and the healthcare team.

Irrespective of the tools used for assessing functional recovery, the patient's socio-cultural background should be considered when assessing functional recovery.

Factors influencing functional recovery

When seeking for the achievement of functional recovery, the combined influence of stressful life events, substance abuse, socioeconomic conditions, and family relationships, should be considered.

Although negative symptoms have a great impact on functioning, clinicians should not focus exclusively on symptom remission when considering functional recovery.

Psychosocial interventions and functional recovery

Psychosocial interventions are necessary to achieve functional recovery. A combination of various therapies (including social skills training, family therapy, cognitive rehabilitation, social cognitive training, and occupational programs) is likely to be most useful in achieving functional recovery.

Pharmacological treatment and functional recovery

Functional recovery should be considered in decision-making on pharmacological treatments.

The perspective of patients and their relatives on functional recovery

The attitudes of all stakeholders (i.e., patients, their relatives, and clinicians) influence functional recovery. Hence, when seeking for achieving functional recovery, all these perspectives should be taken into account. 
The scope of the results presented herein must be weighed considering some limitations of our work. First, the selection of experts was neither systematic nor randomized. Alternatively, we recruited specialists in the management of schizophrenia from various Spanish regions. Thus, although all experts must account at least 10 years of clinical practice, a selection bias cannot be ruled out. Second, some items expressing mutually incompatible ideas yielded inconsistent results. Items affected by this phenomenon were discussed and eventually not considered for drawing the final conclusions. Finally, the resulting recommendations were not drawn following a consensus process, but as an interpretation of the agreements and disagreements resulting from the Delphi process. Nevertheless, due to the expected heterogeneity on the concept, we deemed it more appropriate to address the conclusions by weighing the scope of each result carefully and addressing the inconsistencies that might arise from the responses of the panel of experts.

\section{Conclusions}

Despite the lack of a standardized definition of functional recovery in schizophrenia, clinicians are aware of this approach, show a trend towards a common construct of this concept, and consider functional recovery in their day-to-day practice, albeit in a non-formal way. In our experience, 57 Spanish psychiatrists reached a consensus on $85 \%$ of items addressing various aspects of functional recovery in schizophrenia. Based on the results of this consensus and their consistency with the information available in the literature, the experts of this panel provide a list of recommendations (Table 2).

\section{Additional file}

Additional file 1: Results of the Delphi consensus. Score (median and interquartile range) of each item of the questionnaire. (PDF $397 \mathrm{~kb}$ )

\section{Abbreviations}

GAF: Global Assessment Functioning; GAS: Global Assessment Scale; HoNOS: Health of the Nation Outcome Scale; PSP: Personal and Social Performance; SOFAS: Social and Occupational Functioning Assessment Scale; WHODAS: World Health Organization Disability Assessment Schedule

\section{Acknowledgements}

Medical writing assistance was provided by Dr. Gerard Carot-Sans, PhD, and Medical Writers 5.0 on behalf of Janssen. The authors gratefully acknowledge the time and effort of the panel members: Adolfo Benito, Ainara Arnaiz, Ana Catalán, Ana González-Pinto, Ana Landa, Celso Iglesias, Clemente García-Rizo, Consuelo Llinares, David Fraguas, Demetrio Mármol, Eduard Parellada, Fernando Montiano, Francisco Salido, Ignacio García, Ignacio Zarranz, Jesús Mesones, Jesús Morillas, José A. Alcalá, Jose L. Montero, José M. Montes, José M. Olivares, José R. Gutiérrez, Juan A. Martínez, Juan J. Fernández, Luis Docasar, Luis Gutiérrez, Luis San, M. Ángeles Escudero, Manuel Serrano, M. Luisa Terradillos, Mariano Villar, Marina Díaz, Mario Páramo, Marta Alonso, Mercedes Hellín, Migdyrai Martín, Miguel Lliteras, Miquel Bioque, Nieves Prieto, Pedro Sopelana, Pilar Saiz, Rosa Gutiérrez, Rosa Molina, Rubén T. López, Samuel Leopoldo, Santiago Ovejero, Selman Franco, Sergio Sánchez, Tomás Castelló, Vicente Tordera M. José Escartín, José M. Mongil, Julián Rodríguez.

\section{Funding}

This project was funded by Janssen. The funding body participated in study design and data interpretation.

\section{Availability of data and materials}

The datasets used and/or analyzed during the current study are available from the corresponding author on reasonable request.

\section{Authors' contributions}

GL, JLG, PS, MM, JVP, PG-P, BH, and MR have made substantial contributions to the conception and design of this consensus process, have revised all manuscript drafts critically, and have approved the final version of the manuscript. All co-authors agree to be accountable for all aspects of the work in ensuring that questions related to the accuracy or integrity of any part of the work were appropriately addressed and resolved.

\section{Ethics approval and consent to participate}

Not applicable.

\section{Competing interests}

G. Lahera has received research grant support from the Ministry of Health (Spain), CIBERSAM, Lilly, and Janssen, and has worked as an advisor board member for Lundbeck, Otsuka, Janssen, and Pfizer. J. L. Gálvez has received grants from Janssen, Lundbeck, Pfizer and Servier. P. Sánchez has received research grant support from the Ministry of Health (Spain), has worked as an advisor board member for Janssen and Ferrer, and has worked as a speaker for Janssen. M. Martínez has worked as a speaker and/or advisor and/or researcher in projects promoted by Esteve, GlaxoSmithKline, Janssen-Cilag, Lilly, Lundbeck, Otsuka, Pfizer, Servier, Roche, and Rovi. J. V. Pérez has worked as a speaker for Janssen and Lundbeck. P. García-Portilla has been a consultant to and/or has received honoraria/grants from Alianza OtsukaLundbeck, CIBERSAM, European Comission, Instituto de Salud Carlos III, Janssen-Cilag, Lilly, Lundbeck, Otsuka, Pfizer, Servier, Roche, and Rovi.

B. Herrera is currently employed by Janssen-Cilag S. A. M. Roca has received research grant support from Health Institute Carlos III, Ministry of Economy and Competitiveness, European Union ERDF as worked as a speaker and/or advisorin project promoted by Janssen, Lundbeck and Pfizer.

\section{Publisher's Note}

Springer Nature remains neutral with regard to jurisdictional claims in published maps and institutional affiliations.

\section{Author details}

'Departamento de Medicina y Especialidades Médicas, Facultad de Medicina, Universidad de Alcalá, Plaza de San Diego, s/n, 28801 Alcalá de Henares, Madrid, Spain. ${ }^{2}$ Centro de Investigación Biomédica en Red de Salud Mental (CIBERSAM), Madrid, Spain. ${ }^{3}$ Unidad de Salud Mental Comunitaria del Hospital Universitario Virgen del Rocio, Av. Manuel Siurot, S/N, 41013 Sevilla, Spain. ${ }^{4}$ Unidad de Psicosis Refractaria, Hospital Psiquiátrico de Álava-Osakidetza, C/ Álava, n45, 01006 Vitoria - Gasteiz, Spain. ${ }^{5}$ Facultad de Medicina, Universidad del País Vasco-Euskal Herriko Unibertsitatea, Leioa, Spain. ${ }^{6}$ Hospital Royo Villanova, Avda. San Gregorio, s/n, 50015 Zaragoza, Spain. ${ }^{7}$ Centro de Salud Mental Fuente San Luis, Hospital Universitario Doctor Peset, Av. de Gaspar Aguilar, 90, 46017 València, Spain. ${ }^{8}$ Área de Psiquiatría, Facultad de Medicina, Universidad de Oviedo, Av. Julián Clavería, s/n, 33006 Oviedo, Asturias, Spain. ${ }^{9}$ Medical Affairs Department, Janssen-Cilag, Avenida Partenón, 161 (Campo de las Naciones), S. A, 28042 Madrid, Spain. ${ }^{10}$ Institut Universitari d'Investigació en Ciencies de la Salut (IUNIS), RedIAPP, Hospital Juan March, Universidad de las Islas Baleares, Cra. de Valldemossa, km 7.5., Palma de Mallorca, (Illes Balears), Spain.

Received: 2 October 2017 Accepted: 22 May 2018

Published online: 05 June 2018

\section{References}

1. Working Group of the Clinical Practice Guideline for Schizophrenia and Incipient Psychotic Disorder. Clinical Practice Guideline for Schizophrenia and Incipient Psychotic Disorder [Internet]. Clinical P. 2009; [cited 2018 June 1]. Available from: http://www.guiasalud.es/GPC/GPC_495_Schizophrenia compl_en.pdf 
2. Bellack AS. Scientific and consumer models of recovery in schizophrenia: concordance, contrasts. and implications Schizophr Bull. 2006;32:432-42.

3. Harvey PD. Functional recovery in schizophrenia: raising the bar for outcomes in people with schizophrenia. Schizophr Bull. 2009;35:299.

4. Harvey PD, Bellack AS. Toward a terminology for functional recovery in schizophrenia: is functional remission a viable concept? Schizophr Bull. 2009;35:300-6.

5. Kern RS, Glynn SM, Horan WP, Marder SR. Psychosocial treatments to promote functional recovery in schizophrenia. Schizophr Bull. 2009;35:347-61.

6. Liberman RP. Recovery from schizophrenia: form follows functioning. World Psychiatry. 2012;11:161-2

7. Lieberman JA, Drake RE, Sederer LI, Belger A, Keefe R, Perkins D, et al. Science and recovery in schizophrenia. Psychiatr Serv. 2008;59:487-96.

8. Slade M, Schrank B. Recovery in psychiatry. Psychiatr Bull. 2007;31:321-5.

9. Crespo-Facorro B, Bernardo M, Argimon JM, Arrojo M, Bravo-Ortiz MF, Cabrera-Cifuentes A, et al. Effectiveness, efficiency and efficacy in the multidimensional treatment of schizophrenia: rethinking project [article in Spanish]. Rev Psiquiatr Salud Ment. 2017;10:4-20.

10. Liberman RP, Kopelowicz A, Ventura J, Gutkind D. Operational criteria and factors related to recovery from schizophrenia. Int Rev Psychiatry. 2002;14: 256-72.

11. Anthony WA. Recovery from mental illness: the guiding vision of the mental health service system in the 1990s. Psychosoc Rehabil J. 1993;16:11.

12. Liberman RP. Recovery from disability. Man. Psychiatr. Rehabil. Washington: apa; 2008.

13. Menendez-Miranda I, Garcia-Portilla MP, Garcia-Alvarez L, Arrojo M, Sanchez $P$, Sarramea F, et al. Predictive factors of functional capacity and real-world functioning in patients with schizophrenia. Eur Psychiatry. 2015;30:622-7.

14. Harvey PD. Assessment of everyday functioning in schizophrenia: implications for treatments aimed at negative symptoms. Schizophr Res. 2013;150:353-5.

15. P a L, Kopelowicz A, Ventura J, Gutkind D. Operational criteria and factors related to recovery from schizophrenia. Int Rev psychiatry. 2002;14:256-72.

16. Onken SJ, Craig CM, Ridgway P, Ralph RO, Cook JA. An analysis of the definitions and elements of recovery: a review of the literature. Psychiatr. Rehabil. J. 2007;31:9.

17. Peña J, Ibarretxe-Bilbao N, Sánchez P, Iriarte MB, Elizagarate E, Garay MA, et al. Combining social cognitive treatment, cognitive remediation, and functional skills training in schizophrenia: a randomized controlled trial. np Schizophr. 2016;2:16037.

18. Bond GR, Drake RE, Becker DR. An update on randomized controlled trials of evidence-based supported employment. Psychiatr. Rehabil. J. 2008:31:280

19. Crowther RE. Helping people with severe mental illness to obtain work: systematic review. BMJ. 2001;322:204-8.

20. Rog DJ. The evidence on supported housing. Psychiatr Rehabil J. 2004;27: 334.

21. Tsemberis S, Gulcur L, Nakae M. Housing first, consumer choice, and harm reduction for homeless individuals with a dual diagnosis. Am J Public Health. 2004:94:651-6.

22. Lahera G, Pérez-Fuster V, Gálvez JL, Martínez M, Sánchez P. Roca M. Is it possible to achieve functional recovery in schizophrenia? A qualitative and quantitative analysis of psychiatrist's opinion. Actas Esp Psiquiatr palabras clave Recuper. Func. Actas Esp Psiquiatr. 2016;4444:97-106.

23. Green KC, Armstrong JS, Graefe A. Methods to elicit forecasts from groups: Delphi and prediction markets compared. 2007:

24. Rowe G, Wright $\mathrm{G}$. Expert opinions in forecasting: the role of the Delphi technique. In: Principles of forecasting. Boston: Springer; 2001. pp.125-44.

25. Sinha IP, Smyth RL, Williamson PR. Using the Delphi technique to determine which outcomes to measure in clinical trials: recommendations for the future based on a systematic review of existing studies. PLoS Med. 2011;8: e1000393.

26. Emsley R, Chiliza B, Asmal L, Lehloenya K. The concepts of remission and recovery in schizophrenia. Curr Opin Psychiatry. 2011;24:114-21.

27. Harrow M, Grossman LS, Jobe TH, Herbener ES. Do patients with schizophrenia ever show periods of recovery? A 15-year multi-follow-up study. Schizophr Bull. 2005;31:723-34.

28. Browne J, Penn DL, Meyer-Kalos PS, Mueser KT, Estroff SE, Brunette MF, et al. Psychological well-being and mental health recovery in the NIMH RAISE early treatment program. Schizophr Res. 2016;11:174-81.

29. Slade M, Longden E. Empirical evidence about recovery and mental health. BMC Psychiatry. 2015;15:285.
30. Farkas M. The vision of recovery today: what it is and what it means for services. World Psychiatry. 2007:6:4-10.

31. Sabbag S, Twamley EM, Vella L, Heaton RK, Patterson TL, Harvey PD. Assessing everyday functioning in schizophrenia: not all informants seem equally informative. Schizophr Res. 2011;131:250-5.

32. Bowie CR, Twamley EW, Anderson H, Halpern B, Patterson TL, Harvey PD. Self-assessment of functional status in schizophrenia. J Psychiatr Res. 2007; 41:1012-8.

33. Harvey PD, Sabbag S, Prestia D, Durand D, Twamley EW, Patterson TL. Functional milestones and clinician ratings of everyday functioning in people with schizophrenia: overlap between milestones and specificity of ratings. J Psychiatr Res. 2012;46:1546-52.

34. Leifker FR, Bowie CR, Harvey PD. Determinants of everyday outcomes in schizophrenia: the influences of cognitive impairment, functional capacity, and symptoms. Schizophr Res. 2009:115:82-7.

35. McKibbin C, Patterson TL, Jeste DV. Assessing disability in older patients with schizophrenia. Results From the WHODAS-II J Nerv Ment Dis. 2004;192: 405-13.

36. Strauss JS, Breier A. The Vermont longitudinal study of persons with severe mental illness, I: methodology, study sample, and overall status 32 years later. Am J Psychiatry. 1987;144:718-26.

37. Torgalsbøen A-K, Rund BR. Lessons learned from three studies of recovery from schizophrenia. Int. Rev. Psychiatry. 2002;14:312-7.

38. Giraud-Baro E, Dassa D, De Vathaire F, Garay RP, Obeid J. Schizophreniaspectrum patients treated with long-acting injectable risperidone in real-life clinical settings: functional recovery in remitted versus stable, non-remitted patients (the EVeREST prospective observational cohort study). BMC Psychiatry. 2016;16:8.

39. Hopper K, Wanderling J. Revisiting the developed versus developing country distinction in course and outcome in schizophrenia: results from ISOS, the WHO collaborative followup project. Schizophr Bull. 2000; 26:835-46.

40. Bowie CR, Reichenberg A, Patterson TL, Heaton RK, Harvey PD. Determinants of real-world functional performance in schizophrenia subjects: correlations with cognition, functional capacity, and symptoms. Am J Psychiatry. 2006;163:418-25.

41. Robinson DG, Woerner MG, McMeniman M, Mendelowitz A, Bilder RM. Symptomatic and functional recovery from a first episode of schizophrenia or schizoaffective disorder. Am J Psychiatry. 2004;161:473-9.

42. Remington G, Foussias G, Fervaha G, Agid O, Takeuchi H, Lee J, et al. Treating negative symptoms in schizophrenia: an update. Curr Treat Options Psychiatry. 2016;3:133-50.

43. Link BG, Struening EL, Neese-Todd S, Asmussen S, Phelan JC. Stigma as a barrier to recovery: the consequences of stigma for the self-esteem of people with mental illnesses. Psychiatr Serv. 2001;52:1621-6.

44. Pattyn E, Verhaeghe M, Sercu C, Bracke P. Public stigma and sell-stigma: differential association with attitudes toward formal and informal help seeking. Psychiatr Serv. 2014;65:232-8

45. Sánchez P, Peña J, Bengoetxea E, Ojeda N, Elizagárate E, Ezcurra J, et al. Improvements in negative symptoms and functional outcome after a new generation cognitive remediation program: a randomized controlled trial. Schizophr Bull. 2014;40:707-15.

46. Marder SR, Lebell M, Zimmerman K, Liberman RP. Two-year outcome of social skills training and group psychotherapy for outpatients with schizophrenia. Age. 1996:38:37-9.

47. Glynn SM, Marder SR, Liberman RP, Blair K, Wirshing WC, Wirshing DA, et al. Supplementing clinic-based skills training with manual-based community support sessions: effects on social adjustment of patients with schizophrenia. Am J Psychiatry. 2002;159:829-37.

48. Nowak I, Sabariego C, Świtaj P, Anczewska M. Disability and recovery in schizophrenia: a systematic review of cognitive behavioral therapy interventions. BMC Psychiatry. 2016;16:228.

49. Färdig R, Fredriksson A, Lewander T, Melin L, Mueser KT. Neurocognitive functioning and outcome of the illness management and recovery program for clients with schizophrenia and schizoaffective disorder. Nord J Psychiatry. 2016;70:430-5.

50. Wunderink L, Nieboer RM, Wiersma D, Sytema S, Nienhuis FJ. Recovery in remitted first-episode psychosis at 7 years of follow-up of an early dose reduction/discontinuation or maintenance treatment strategy long-term follow-up of a 2-year randomized clinical trial. JAMA Psychiatry. 2013;70: 913-20. 
51. Undurraga J, Murru A, Vieta E. Early medication discontinuation on long-term recovery outcome in first-episode psychosis. JAMA Psychiatry. 2014;71:206-7.

52. Rosenheck R, Tekell J, Peters J, Cramer J, Fontana A, Xu W, et al. Does participation in psychosocial treatment augment the benefit of clozapine? Department of Veterans Affairs Cooperative Study Group on clozapine in refractory schizophrenia. Arch Gen Psychiatry. 1998;55:618-25.

53. Schooler NR, Keith SJ, Severe JB, Matthews SM. Maintenance treatment of schizophrenia: a review of dose reduction and family treatment strategies. Psychiatr Q. 1995;66:279-92.

54. Schooler NR, Keith SJ, Severe JB, Matthews SM, Bellack AS, Glick ID, et al. Relapse and rehospitalization during maintenance treatment of schizophrenia. The effects of dose reduction and family treatment. Arch Gen Psychiatry. 1997;54:453-63.

55. Crespo-Facorro B, Roiz-Santiáñez R, Pérez-Iglesias R, Pelayo-Terán JM, Rodríguez-Sánchez JM, Tordesillas-Gutiérrez D, et al. Effect of antipsychotic drugs on brain morphometry. Prog Neuro-Psychopharmacology Biol Psychiatry. 2008:32:1936-43.

56. Lieberman JA, Tollefson GD, Charles C, Zipursky R, Sharma T, Kahn RS, et al. Antipsychotic drug effects on brain morphology in first-episode psychosis. Arch Gen Psychiatry. 2005;62:361.

57. Koshikawa Y, Takekita Y, Kato M, Sakai S, Onohara A, Sunada N, et al. The comparative effects of risperidone long-acting injection and paliperidone palmitate on social functioning in schizophrenia: a 6-month, open-label, randomized controlled pilot trial. Neuropsychobiology. 2016;73:35-42.

58. Pandina G, Bilder R, Turkoz I, Alphs L. Identification of clinically meaningful relationships among cognition, functionality, and symptoms in subjects with schizophrenia or schizoaffective disorder. Schizophr Res. 2013;143:312-8.

59. Correll CU, Leucht S, Kane JM. Lower risk for tardive dyskinesia associated with second-generation antipsychotics: a systematic review of 1-year studies. Am J Psychiatry. 2004;161:414-25.

60. Leucht S, Pitschel-Walz G, Abraham D, Kissling W. Efficacy and extrapyramidal side-effects of the new antipsychotics olanzapine, quetiapine, risperidone, and sertindole compared to conventional antipsychotics and placebo. A meta-analysis of randomized controlled trials. Schizophr Res. 1999;35:51-68.

61. Leucht S, Corves C, Arbter D, Engel RR, Li C, Davis JM. Second-generation versus first-generation antipsychotic drugs for schizophrenia: a metaanalysis. Lancet. 2009;373:31-41.

\section{Ready to submit your research? Choose BMC and benefit from}

- fast, convenient online submission

- thorough peer review by experienced researchers in your field

- rapid publication on acceptance

- support for research data, including large and complex data types

- gold Open Access which fosters wider collaboration and increased citations - maximum visibility for your research: over $100 \mathrm{M}$ website views per year

At BMC, research is always in progress.

Learn more biomedcentral.com/submissions 